Return to work after coronary artery surgery for angina

SIR,-The proportion of patients returning successfully to work after coronary artery bypass grafting by the Scottish team (16 December, $p$ 1680) is so astonishingly different from the American findings ${ }^{1}$ as to make one ask wherein lies the secret of their success. Is it possible that their patients were a group who had "given up" or had "been given up" and therefore were open to motivation by any reasonably energetic group of therapists? Is it possible that Wallwork and his colleagues employed the placebo effect described so well by Preston"? Without comparison of surgery with another form of rehabilitation no conclusion can be drawn about its specific effects.

Peter Nixon NORMAN WEINSTOCK

Charing Cross Hospital (Fulham),

London W6

Barnes, G K, et al, fournal of the American Medical Association, 1977, 238, 1259.
. Association, 1977, 238, 1259.
Review. N, Cowonary Artery Surgery: A Critical
Revik, Raven Press, 1977.

\section{Gonococcal arthritis}

SIR,-Dr Dermot Murray (6 January, p 22) does well to emphasise that his patient was genitally asymptomatic and he states that this is a feature of men with the gonococcalarthritis syndrome. I would like to emphasise, however, that in our series of 16 patients, ${ }^{1} 13$ of whom were women, only three were initially seen in the department of venereology; others presented to general physicians, rheumatologists, or dermatologists. Although the ESR is almost invariably raised in these patients, the physician must be reminded that it is commonly so in patients with an inflammatory non-arthropathy of this type, be it due to Reiter's disease or gout; and it would be foolhardy to make this the basis of the diagnosis of the gonococcal arthritis syndrome.

It must be emphasised once again that specimens of synovial fluid should always be cultured anaerobically in patients with unexplained arthropathies, although the yield of positive results is seldom more than $25 \%$ in the most capable hands. Another source of positive culture results not mentioned by $\mathrm{Dr}$ Murray is the rectum.

May I repeat that it is mandatory to exercise a high index of suspicion in all patients presenting with an unexplained arthropathy of this type?

Martin SEIfERT

Department of Rheumatology,

St Mary's Hospital

'Seifert, M H, et al, Annals of the Rheumatic Diseases, $1974,22,140$.

SIR,-There has lately been revived interest in the natural history of gonorrhoea with pyrexia and skin and joint lesions-disseminated gonococcal infection or benign gonococcaemia. ${ }^{12}$ Despite this, it would appear that the diagnosis is still frequently hard to come by in Britain. The case of the patient described by Lieutenant-Colonel Dermot Murray (6 January, p 22) took six weeks to clarify.

I can personally recall two cases in six years, one of which was undiagnosed and in retrospect may well have been disseminated gonococcal infection; in the other case the diagnosis came to light only after prolonged and intensive investigations. Our differential diagnosis included meningococcaemia, typhoid fever, staphylococcal septicaemia, and miliary tuberculosis. It should be realised that, in addition to appropriate culture specimens taken from the frequently asymptomatic urogenital tract, pharynx, and rectum, ${ }^{3}$ other bacteriological specimens should be taken according to the clinical state of the disease. Holmes and colleagues" ${ }^{3}$ show clearly that there are two stages to be considered-an early "septicaemic" one, when cultures of blood often give positive and those of the joint negative results, and a later "septic joint" stage when aspirates of joint fluid may well harbour gonococci.

One wonders whether cases of disseminated gonococcal infection which present to differing specialties would be diagnosed more rapidly and more often if we regularly used the expertise of the consultant in infectious diseases. His counterpart in North America is apparently called on after the first unexplained spike on the temperature chart (S Russell, personal communication).

Special Clinic,

Royal Infirm
Sheffield

' Knapp, J S, and Holmes, K K, fournal of Infectious Diseases,

Inger, L, Petersen, B H, and Brooks, G, fournal of Laboratory and Clinical Medicine, 1978, 92, 211

Internal Medicine, 1971, 74, 979.
In, H N, Annals of

\section{Hepatotoxic effects of repeated} anaesthetics

SIR,-Dr William $H$ W Inman and Dr William W Mushin (25 November, p 1455) have again drawn attention to the potential hepatotoxic effects of repeat administrations of halothane, particularly within a short period of time. Enflurane may offer advantages in this respect. Over the past two and a half years we have organised a large-scale study of liver enzymes following repeated anaesthetics. A preliminary analysis of the findings shows a $37 \%(25 / 68)$ incidence of abnormal enzymes following repeat halothane, compared with $14 \%(8 / 59)$ after repeat enflurane in a similar patient population.

Details of this study will be reported in full.

J W DUNDEE G W BLACK DESMOND W NEILL

Department of Anaesthetics,

Queen's University of Belfast, Belfast

\section{Seat belts and the safe car}

SIR,-Mr J A E Primrose is, of course, completely correct in drawing the attention of your readers (13 January, p 122) to the sorry situation in this country with regard to laminated glass in vehicle windows and the failure, on grounds of cost, to ensure its compulsory use in all new vehicles. There is no doubt that all ophthalmologists would strongly support him in the efforts to eliminate the continuing danger arising from the failure of successive administrations to make appropriate regulations.

Regrettably, one has to dissent from a suggestion that the universal use of laminated glass would be a satisfactory alternative to the universal use of car safety belts. Not all injury, and certainly not all ocular injury, is caused merely by flying glass or projection through windscreens. The inertial forces of a human body faced with total stop at even $16 \mathrm{kph}$ (10 $\mathrm{mph}$ ) requires something more than simply being surrounded by unsplinterable glass.

It should not be necessary to point out that this is not of course a situation of alternatives and that there is every reason in the world why both these measures could be made universal practice, and that speedily: windscreens by straightforward government regulation, and belts through the most widespread dissemination among the public at large of knowledge of the appalling extent and nature of the largely avoidable injury arising out of their failure to use these devices-as $\mathrm{Mr} \mathrm{W} \mathrm{H}$ Rutherford urges: the same issue.

The bizarre and irrelevant replies, including accusations of everything from fascism to being a "flat-earther," following the publication of letters in the public media, illustrate how widespread still is the failure of understanding in the public at large.

M J GILKES

Sussex Eye Hospital

Brighton, Sussex

\section{Bicycle accidents}

SIR,-Cycling in London at least (6 January, p 39) could be made a great deal safer by one simple measure, and that is to ensure that the nearside metre of road surface is kept free from holes and projections-that is, smooth. Our capital is appalling in this respect. Brixton Hill is a good example. There are two narrow and busy traffic lanes, and frequent deep holes and raised obstacles near the kerb. A cyclist, possibly travelling at some speed, has two choices: either to swing out suddenly without warning or to continue (possibly unaware) and risk buckling his front wheel and going over the handlebars or buckling his anatomy, or both.

J P W WALTER

London E3

\section{Ergotamine tartrate overdosage}

SIR,-For many years ergotamine tartrate has been used in the treatment of migraine, and in some patients the response to this drug is dramatic. However, recent experience has shown that the dose of this drug must be carefully adjusted because too much ergotamine in itself may give rise to side effects, including nausea, malaise, aching legs, irritable bowel action, and headache.

Ergotamine tartrate may be prescribed by mouth, by suppository, by inhalation, or by injection. If given by mouth, it should be in a form that is readily absorbed; and not more than $1 \mathrm{mg}$ or $2 \mathrm{mg}$ should be given for each attack. Absorption of ergotamine tartrate is probably improved by giving a tablet of $10 \mathrm{mg}$ of metaclopramide (Maxolon) ten minutes beforehand. The apparent need for the patient to take more ergotamine in an attack is probably due to poor absorption. If the drug is given in the form of a suppository, the dose should be $1 \mathrm{mg}$ or $2 \mathrm{mg}$; if it is inhaled, two or three puffs $(0.72 \mathrm{mg}$ or $1.08 \mathrm{mg}$ ) are recommended; and, if it is 
injected intramuscularly, the recommended dose is $0.25 \mathrm{mg}$.

Classical or common attacks of migraine rarely occur more than two or three times a week, so that the weekly dose of ergotamine tartrate should not exceed $6 \mathrm{mg}$. Patients with cluster headache may, however, require higher doses, but only over a relatively short period. Ergotamine tartrate should not be used prophylactically.

Overdosage with ergotamine tartrate is common, and has been reported as affecting up to $10 \%$ of patients attending a migraine clinic. Mild toxic symptoms, including nausea, vomiting, headache, and a feeling of vague ill health may occur, symptoms which are similar to those of an attack of migraine. Many patients with these symptoms imagine that their migraine is not controlled, take more tablets, and thus establish a vicious circle. The more serious features of ergotism -for example, burning pain, venous thrombosis, and gangrene-are rare.

At a clinic supported by the Migraine Trust it has been found that patients recover more quickly if they can go to sleep, and a significant proportion of those coming to the clinic for treatment of an acute attack do this. In these circumstances only about one in ten of those attending for the relief of an acute attack of either classical or common migraine requires ergotamine tartrate. Most patients improve with an antiemetic, a simple analgesic, and a sedative.

$\begin{array}{ll}\text { J N BLAU } & \text { K M HAY } \\ \text { MACDONALD CRITCHLEY } & \text { JOHN MARSHALL } \\ \text { R W GILLIATT } & \text { F CLIFFORD ROSE } \\ \text { RAYMOND GREENE } & \text { J W ALDREN TURNER } \\ \text { EDDA HANINGTON } & \text { MARCIA WILKINSON }\end{array}$

The Migraine Trust

London WC1

\section{Tranexamic acid in chronic urticaria}

SIR,-Following the short report (26 August p 608) from Drs R A Thompson and D D Felix-Davies on the successful use of tranexamic acid in "idiopathic" recurrent angioneurotic oedema, I tried this drug on two patients with previously intractable chronic urticaria. One had been investigated at a leading skin hospital, no cause or effective treatment having been found. The other patient presented to me with recurrent urticaria following exertion and showed no response to antihistamines. Both were given tranexamic acid $1 \mathrm{~g}$ four times daily, and both reported an appreciable reduction in the frequency and the severity of their attacks, which was sustained when the dose was reduced to a maintenance level of $0.5 \mathrm{~g}$ twice daily. Perhaps a trial of this drug is merited in other patients with this troublesome condition.

DARRYL TANT

Luton, Beds

\section{What is a cohort?}

SIR,-Dr V H Springett has rightly pointed out the correct use of the term "cohort" (13 January, $p$ 126). As he says, the term was introduced by Frost ${ }^{1}$ and this valuable method of epidemiological analysis is usually referred to as "Frost's method." I think it ought to be recognised that the method was in fact devised some years earlier by Andvord, ${ }^{2}$ who used the Norwegian word kull ("brood" or "litter") to designate all members of a population born within a particular time period (in Andvord's paper five years). Reference to his paper will show that he used the method exactly in the way subsequently adopted by Frost and that his curves showing tuberculosis mortality rates by age in consecutive kull groups are the prototype of those published in Frost's later paper.

In Frost's paper (posthumously published in 1939, probably written in 1938) he stated that the original idea was Andvord's and gave the relevant reference. If eponymous terms are to be used in medicine it is surely right that the names be those of the true originators.

London $\mathrm{N} 3$

A L JACOBS

${ }^{1}$ Frost, W H, American fournal of Hygiene, 1939, 30, 91. Andvord, K F,

\section{Not the language of medicine}

SIR,-In his reply (13 January, p 120) to your leading article "Not the language of medicine," Lord Smith of Marlow appears to be content that the executive director of the Royal Society of Medicine replied on his behalf and in his absence to the writer of a long critical letter to the president, but this was unlikely to have satisfied the writer. Those of us who enjoy the services of personal secretaries expect them to acknowledge our mail in our absence, deal with urgent inquiries, and tell our correspondents that we will answer other points on our return. Could not a similar arrangement be made at the RSM for a president who has said he wishes to be "accessible" ? Important as the complaints are, they could surely wait for the president's return and his personal attention.

Incidentally, had Lord Smith wished to answer some of these doubts "in full and in public," as your leader urges, he might in his lengthy reply have devoted some of the space to them rather than to his personal philosophy concerning the "freedom to disagree."

London NW8

BARBARA Evans

\section{Cataracts}

SIR,-Referring to Mr P A Gardiner's paper on cataracts (6 January, p 36), I should like to point out to doctors that they have a good opportunity to observe the development of their own cataracts if - as they should be-they are in possession of a microscope. No slide is required; plain daylight illumination of the visual field is sufficient. If the eye is removed about $1-2 \mathrm{~cm}$ from the ocular and the condenser diaphragm closed by about half the cataract obscures the visual field so clearly that it can easily be drawn. A comparison of such drawings made at intervals of about three weeks clearly shows the progress of the lenticular opacity.

Pinner, Middx

E ELKAN

SIR,-Mr P A Gardiner (6 January, p 38) very rightly points out that surgery for cataract is useless if the retina is unhealthy. I can think of nothing more heart breaking for a patient than to wait a long time for cataract surgery in the confident expectation that sight would be restored, only to find that the removal of the lens is in vain.

During the years from 1966 during which I provided ultrasonic diagnostic services at Moorfields High Holborn, I was astonished how few such patients were sent for exclusion of retinal detachment. The ultrasonic diagnosis of eye tumours admittedly requires much experience and preferably modern equipment, but Mundt and Hughes ${ }^{1}$ showed how easily a retinal detachment may be detected with the simplest portable unit. Now that ultrasonic apparatus is widely available a cheap ophthalmic transducer can be connected. When the device is applied to the closed lids with a little jelly the absence of a detachment can be shown in an examination lasting barely a minute with hardly any training.

\section{DOUGLAS GoRDON}

The City University,

London EC1

${ }^{1}$ Mundt, $\mathrm{H}$, and Hughes, W F, American fournal of Ophthalmology, 1956, 41, 488 .

\section{Kielland's forceps}

SIR,-At a time when forceps delivery is being questioned in public, it is reassuring to read in the two papers by Drs Malcolm L Chiswick and David K James (6 January, pp 7 and 10) that in the absence of evidence of fetal distress on cardiotocography, the use of Kielland's forceps was not associated with any significantly increased mortality or significant morbidity. The only difference between the study group and the "control" group of spontaneous deliveries was that the former group showed an increase in neonatal "abnormal neurological behaviour." The validity of this observation is questionable in this retrospective study, neonates not having been checked routinely for abnormal neurological behaviour, which was brought to the attention of the paediatrician only if the mother or midwife was concerned. English mothers are more likely to be concerned about their babies if they have been delivered by forceps, as this mode of delivery is not yet regarded as normal in this country.

The increased mortality and morbidity in the whole study group compared with the control group cannot be attributed to the use of Kielland's forceps, since the control group did not have a malrotation necessitating some form of operative intervention. The only way of deciding whether the use of Kielland's forceps increases mortality and morbidity is to randomly allocate cases of malrotation with fetal asphyxia in which vaginal delivery could be considered to different methods such as Kielland's forceps, ventouse extraction, and caesarean section. Then by assessing fetal and maternal outcome one may be able to decide the best way to manage these cases.

M MARESH

Queen Charlotte's Maternity Hospital,

London W6

SIR,-In support of Drs D K James's and $M$ L Chiswick's paper on Kielland's forceps (6 January, $p$ 10), I would like to add the following. Without doubt the only way to avoid the tragedy of a tentorial tear, assuming good technical application of the forceps, is to not exceed a certain force. This emphasises the obvious, that all such rotational deliveries 